\title{
Unsteady Nano-Liquid Spray with Thermal Radiation Comprising CNTs
}

\author{
Taza Gul ${ }^{1}$, Waqar A Khan 2ㅇ, Mehwish Tahir ${ }^{3}$, Rubi Bilal ${ }^{3}$, Ilyas Khan ${ }^{4, *}$ and \\ Kottakkaran Sooppy Nisar ${ }^{5}$ (i)
}

1 Department of mathematics, City University of Science and Information Technology, Peshawar 25000, Pakistan; tazagul@cusit.edu.pk

2 Department of Mechanical Engineering, College of Engineering, Prince Mohammad Bin Fahd University, Al Khobar 31952, Saudi Arabia; wkhan1956@gmail.com

3 Department of Mathematics, Shaheed Benazir Bhutto Women University, Peshawar 25000, Pakistan; mehwishth@gmail.com (M.T.); rbilal04@gmail.com (R.B.)

4 Faculty of Mathematics and Statistics, Ton Duc Thang University, Ho Chi Minh City 72915, Vietnam

5 Department of Mathematics, College of Arts and Sciences, Prince Sattam bin Abdulaziz University, Wadi Aldawaser 11991, Saudi Arabia; n.sooppy@psau.edu.sa

* Correspondence: ilyaskhan@tdtu.edu.vn

Received: 23 January 2019; Accepted: 14 March 2019; Published: 28 March 2019

\begin{abstract}
Carbon nanotubes play a significant role in improving the thermal efficiency of common liquids. The objective of this research is to examine the thin film spray over the surface of a vertical tube through carbon nanotubes (CNTs) nanofluids. Processes for the preparation of the nanofluid and the stable dispersion of the CNTs in water were followed from the available experimental literature. The thickness of the spray pattern was kept variable to control the stability of the spray pattern and to accomplish the suitable heat transmission under the effects of a magnetic field. The pressure supply and rate of the spray were also calculated as a function of the liquid film thickness. The basic governing equations were transformed into nonlinear differential equations by using suitable similarity transformations. The numerical outcomes were obtained by means of the BVPh 2.0 package of the optimal scheme. The influences of the physical quantities like spray rate and variable thickness on the dimensionless velocity, temperature, pressure distribution, Nusselt number were investigated and the results are compared with the existing literature. The comparison was found to be in good agreement. The present results showed that the single-walled carbon nanotubes are more efficient in the enhancement of heat transfer rate compared to the multi-walled carbon nanotubes.
\end{abstract}

Keywords: SWCNTs/MWCNTs; thin film spray; stretching tube; magnetic field; spray rate; OHAM-BVPh 2.0 Package

\section{Introduction}

The heat transfer mechanism plays an important role in industries, biosciences, and engineering. Many conventional fluids such as water, ethylene glycol, and engine oil are used for heat transfer in a thermal system. With the increase of consumption of energy, these conventional fluids are not enough for the fulfillment of modern demands. Numerous researchers imagine distinctive strategies to improve the heat exchange of the fluid. The heat transfer mechanism can be improved by changing the flow geometry, physical condition or by augmenting the thermal efficiency of the liquids. Numerous methods have been invented to improve the heat transfer performance of the liquids. The suspension of nanoparticles in the base fluids gives incredible change in their thermal, mechanical, optical and 
electronic properties because the thermal conductivity of nanoparticles is substantially more than that of fluids. The heat exchange component can be expanded by including metallic or nonmetallic particles in a base liquid, for example, water or ethylene glycol. The heterogeneous suspension of nanosize particles in the base fluid used for heat transfer is termed as nanofluids. Most of the work done on the nanofluids was related to the large-sized nanoparticles, but unfortunately, such nanoparticles have stability issues. The nano liquids were invented by Choi [1]. He clarifies nano liquids as a liquid containing smaller scale little size particles known as nanoparticles about (1-1000 nm) in a measure. These nanoparticles help in enhancing the thermal conductivity of the traditional liquids.

Carbon nanotubes play a significant role to improve the thermal conductivity of the liquids. Carbon nanotubes CNTs were first discovered by [2]. The TEM picture of CNTs was reported by Oberlin et al. [3]. The needle shape nanosize structure, about 4 to $30 \mathrm{~nm}$ in diameter, was innovated by [2] using an arc discharge evaporation method for its synthesis. The development of single-walled carbon nanotubes was carried out in 1993 by two research groups [4,5]. Carbon nanotubes may be divided into two classifications: Single-walled (SWCNTs) and Multi-Walled (MWCNTs). SWCNTs are enclosed by wrapping a layer of carbon with one particle thick layer called graphene into a cylinder. They require a catalyst for their synthesis. Most research in early 1990 reported that CNTs-nanofluids had a lot of importance in both academic and industrial communities and several applications in numerous fields like aerospace, electronics, optical and energy conservation [6,7]. The impact of carbon nanotube (CNT) scattering on the mechanical properties and microstructures of ultra-light frothed cement was studied by Jing and Xiangdong [8]. A sort of uniform and stable CNT scattering arrangement was acquired by including nano-Ce( $\left(\mathrm{SO}_{4}\right)_{2}$. The results demonstrated that CNT scattering increments the compressive and breaking qualities of frothed cement. The impact of CNT scattering on the compressive and breaking qualities of frothed cement is anticipated through reproduction.

The ultra-high thermal conductivity of carbon nanotubes $(2000-6000 \mathrm{~W} / \mathrm{mK})$ is of a higher magnitude compared with aluminum $(237 \mathrm{~W} / \mathrm{mK})$ and aluminum oxides $(40 \mathrm{~W} / \mathrm{mK})$. Consequently, CNTs are the object of great interest in the research area. Due to the higher thermal conductivity and potential properties of carbon nanotubes (CNT), their nanofluids exhibit much higher thermal conductivity and can remove higher heat flux as compared to pure fluid $[9,10]$. Carbon nanotubes have great dispersion properties with most base fluids; this is responsible for their long-term stability. Various techniques have been discovered by different researchers to enhance the thermal conductivities of fluid using CNTs. Kamali and Binesh [11] investigated enhancement of heat transmission using CNTs suspension. Most of the work was performed on multi-walled carbon nanotubes (MWCNT). Pal and Sharma [12] examined the consequence of sintering on the electro and thermophysical properties of CNTs. They examined the synthesis of silver nanocomposite using SWCNTs and MWCNTs by modified molecular level mixing method. They concluded that the comparatively enhanced mechanical and electrical properties of SWCNTs fortified nanocomposites performance better than MWCNTS strengthened nanocomposite, which are related to the high aspect ratio and higher powerful contact surface area of SWCNTs.

After the development of nanofluids, researchers depicted their work in different areas under different boundary conditions. Domairry [13] and Rashidi et al. [14] studied the flow of nanofluids and their significance towards industry and engineering. Heat transforms of motor oil within the sight of both sorts of CNTs between two concentric chambers is displayed in [15]. It was demonstrated that the consideration of nanoparticles maximized the heat conductivity of liquid essentially for both turbulent and laminar flow. The results of the above problem were reviews of SWCNT-motor oil and MWCNT-motor oil. The boundary layer stream of CNTs over a curved extending surface is examined in [16]. The homogeneous response happening in the liquid are executed by first order kinetics. The four types of nanofluids including MWCNTs- $\mathrm{H}_{2} \mathrm{O}, \mathrm{CuO}-\mathrm{H}_{2} \mathrm{O}, \mathrm{SiO}_{2}-\mathrm{H}_{2} \mathrm{O}$, and $\mathrm{CuO}-\mathrm{C}_{2} \mathrm{H}_{6} \mathrm{O}_{2}$, are considered in [17]. The results of physical parameters like skin friction and Nusselt number were incorporated into this work. A comparative examination was performed by different researches using a variety of different models [18]. 
Following Fourier [19], Cattaneo [20] presented an amendment in the Fourier model by including relaxation time for heat transfer. The effective thermal conductivity of the Maxwell model depends on thermal conductivity considered by Walvekar and Faris [21].

The various varieties of the models describe the thermal conductivities of CNTs in different geometries. The researchers tried to improve the thermal conductivity of the CNTs by developing the advanced models [22-26]. Xue [27] suggested a model for the very large axial ratio and repaying the CNTs space dispersal. In the recent study, the Xue [27] model was imposed to calculate the thermal conductivities of the CNTs.

The study of the thin film flow over an extended surface has several applications regarding mechanical engineering and our daily life usages. Thin film flow has been an essential subject of research. Thin film liquid is utilized for making distinctive warmth exchangers and devices in chemical systems, and these applications require a complete understanding of the flow method. The applications include wire and fiber covering, polymer getting ready, etc. This movement is joined to assemble different sorts of sheets, either metallic or plastic. The heat and mass transmission of the thin film flow over stretching sheet have been investigated by Khan et al. [28]. Aziz et al. [29] and Qasim et al. [30] described the unsteady heat transfer flow of the thin film over a stretching sheet. Wang [31] described the flow of a thin film over the stretching cylinder. The thin film spray of the nanofluid over a stretching cylinder has been studied by Khan et al. [32]. The analysis of thin film of $\Upsilon \mathrm{Al}_{2} \mathrm{O}_{3}-\mathrm{H}_{2} \mathrm{O}$ and $\Upsilon \mathrm{Al}_{2} \mathrm{O}_{3}-\mathrm{C}_{2} \mathrm{H}_{6} \mathrm{O}_{2}$ nanofluids spray along a stretching cylinder is investigated by khan et al [33]. Alshomrani and Gul [34] considered the spray of a nanofluid film over the slippery surface of a stretching cylinder. The unsteady and natural convection of the nanofluid over a vertical geometry was studied by Loganathan and Vimala [35].

A variety of mathematical techniques have been used by the researcher for the solution of the proposed models. The Homotopy Analysis Method (HAM) is one of the analytical techniques for the solution of nonlinear differential equations. Liao [36] introduced this method for the first time in his Ph.D. dissertation. Later, Liao [37] further modified this technique by introducing more auxiliary constraints. In recent decades, this method was frequently used by the researchers [38-43] for the solution of nonlinear differential equations. This method was modified by [44] for faster convergence and was named as Optimal Homotopy Analysis Method (OHAM). The convergence control parameters were executed to overcome the convergence of the series solution. The convergence control parameter gives a straightforward method to look at the convergence of the series solution. This technique is genuine and does not rely upon stretching parameters. It gives a suitable way to ensure the convergence of the approximation series. A nonlinear equation is changed into a boundless linear equation with accommodation to choose the related condition and the base functions of the solution. Gul and Firdous [45] examined the experimental and theoretical studies of graphene oxide nanofluid using the OHAM technique.

Based on the above literature review, the aim of this research is set to study the spray coating of a vertical cylinder through CNTs for the heat transfer enhancement applications. The coating materials for the rapid cooling and heat transmission is the second aim of this research. For this purpose, the BVPh 2.0 package, as mentioned in [44,45], is utilized to obtain the 10th order approximations for which the residual error is minimized. Recently, Gul et al. [46] have used the BVP 2.0 package for the suitable range of the parameters up to the 10th order approximation.

\section{Mathematical Formulation}

The two-dimensional unsteady flow of water-based carbon nanotubes is sprayed over a vertical stretching cylinder with radius $r(t)=a \sqrt{1-\alpha t}$. The $z$-axis is considered along the cylinder and $r, u$ are chosen along the radial direction. The cylinder is stretched with the stretching velocity $W_{w}=\frac{2 c}{(1-\alpha t)}$ along the $z$-direction, such that the radius of the cylinder remains identical, as shown in Figure 1. The radius of the cylinder lies in the range between $a(t)$ and $b(t)$. The gravity force $g>0$ shows the downward effect and $g<0$ shows the upward effect during stretching. The single and 
multiwalled carbon nanotubes SWCNTs/MWCNTs and their microscopic view are also shown in Figure 1. The thickness of the liquid film above the free surface is assumed as $h$. The constant $c>0$ shows the stretching and $c<0$ is used for the shrinking of the surface. The term $t$ stands for the time. A constant magnetic field $B_{0}(t)=B_{0}(1-\alpha t)$ is applied in the radial direction.

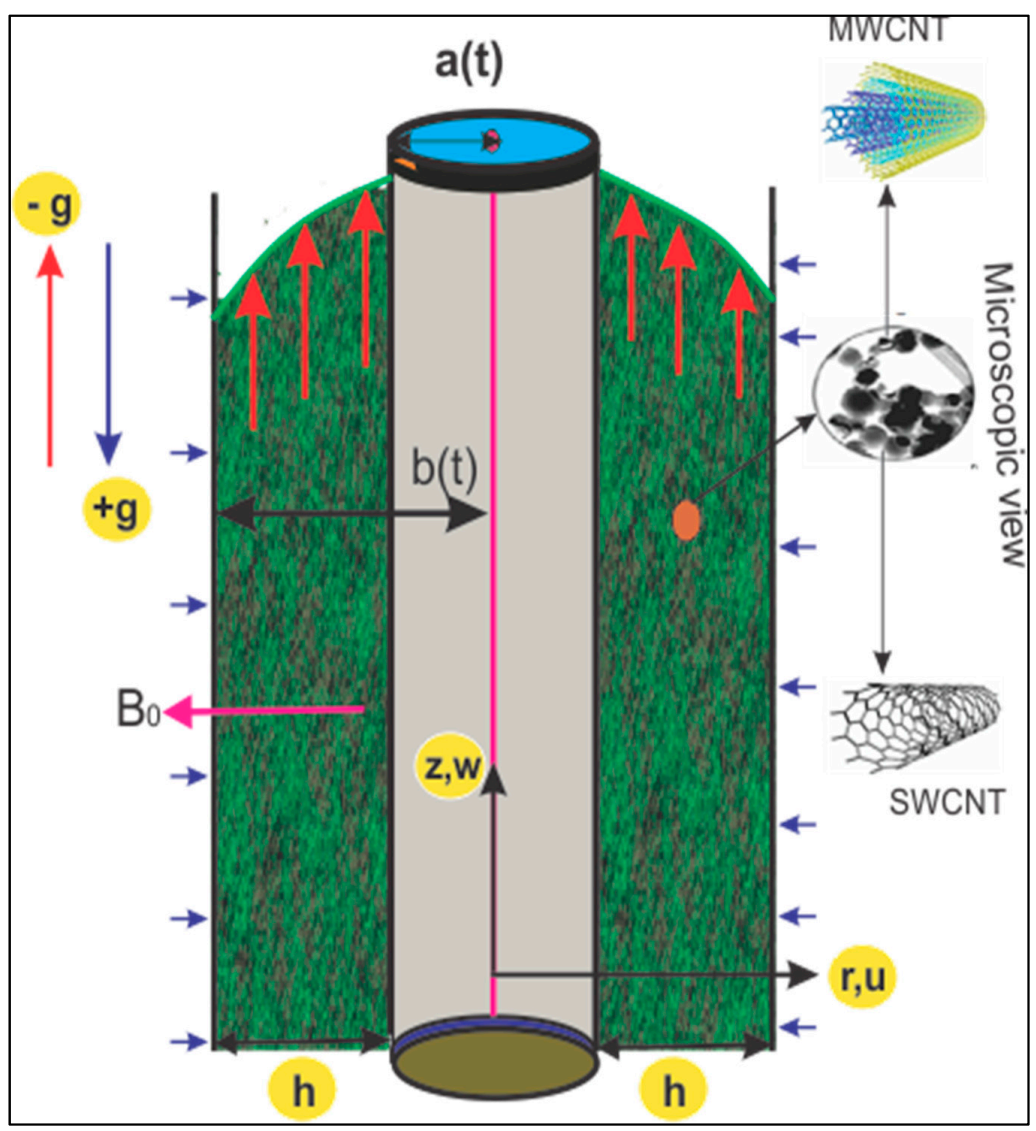

Figure 1. The geometry of the problem.

The basic flow equations are:

$$
\begin{gathered}
\frac{\partial r u}{\partial r}+\frac{\partial r w}{\partial z}=0 \\
\rho_{n f}\left[\frac{\partial w}{\partial t}+\mathrm{u} \frac{\partial w}{\partial r}+\mathrm{w} \frac{\partial w}{\partial z}\right]=\mu_{n f}\left(\frac{\partial^{2} w}{\partial r^{2}}+\frac{1}{r} \frac{\partial w}{\partial r}+\frac{\partial^{2} w}{\partial z^{2}}\right) \pm \mathrm{g}\left(\rho \beta^{*}\right)_{n f}\left(\mathrm{~T}-\mathrm{T}_{b}\right)-\sigma_{n f} B_{0}^{2} u \\
\rho_{n f}\left[\frac{\partial u}{\partial t}+\mathrm{u} \frac{\partial u}{\partial r}+\mathrm{w} \frac{\partial u}{\partial z}\right]=-\frac{\partial p}{\partial r}+\mu_{n f}\left(\frac{\partial^{2} u}{\partial r^{2}}+\frac{1}{r} \frac{\partial u}{\partial r}-\frac{u}{r^{2}}\right) \\
(\rho c p)_{n f}\left[\frac{\partial T}{\partial t}+\mathrm{u} \frac{\partial T}{\partial r}+\mathrm{w} \frac{\partial T}{\partial z}\right]=k_{n f}\left(\frac{\partial^{2} T}{\partial r^{2}}+\frac{1}{r} \frac{\partial T}{\partial r}+\frac{\partial^{2} T}{\partial z^{2}}\right)-\frac{\partial q_{r}}{\partial r} .
\end{gathered}
$$

The velocity components $u(r, z)$ and $w(r, z)$ are directed in the $(r, z)$ directions, $p$ stands for the pressure term, $T$ stands for the temperature field. Moreover, $\rho_{n f}, \mu_{n f}, \beta_{n f},(c p)_{n f}$, and $\kappa_{n f}$ are the density, viscosity, thermal expansion coefficient, heat capacitance and thermal conductivity of carbon nanotubes respectively. The radiative heat flux $q_{r}=\frac{-16 \sigma^{\bullet} T_{b}^{3}}{3 k^{\bullet}}\left(\frac{\partial T}{\partial r}\right)$ was taken from Roseland approximations. The boundary conditions of the above-stated problem are

$$
\begin{gathered}
u=U_{w}, w=W_{w}, T=T_{w}, \text { at } r=r(t), \\
\mu \frac{\partial w}{\partial r}=\frac{\partial T}{\partial r}=0, u=\frac{d b}{d t}, \text { at } r=b .
\end{gathered}
$$


where $r(t)=a \sqrt{1-\alpha t}$ stands for the unsteady radius of the tube and $b(t)$ is the range of the thin nanofluid. $U_{w}=\frac{c a}{\sqrt{\eta(1-\alpha t)}}$ is the suction/ injection velocity, the thickness of the liquid film is denoted by $\delta . T_{w}=T_{a(t)}$ is the surface temperature. The temperature at the liquid film surface is taken as $T=T_{b(t)}$. Where $T_{w}=T_{b(t)}-T_{r e f}\left(\frac{c z^{2}}{v_{f}(1-\alpha t)}\right)$ is taken from the literature [30,31]. $T_{r e f}$ is known as the reference temperature such that $0 \leq T_{r e f} \leq T_{b(t)}$.

The density, viscosity, heat capacitance and thermal conductivity of the CNTs are specified in the Appendix A.

Introducing the similarity transformations to transform the basic governing equations into the dimensionless form as:

$$
\eta=\left(\frac{r}{a \sqrt{(1-\alpha t)}}\right)^{2}, \mathrm{w}=\frac{2 c}{(1-\alpha t)} \frac{d f(\eta)}{d \eta}, u=-\frac{c a}{\sqrt{\eta(1-\alpha t)}} f(\eta), \Theta(\eta)=\frac{T-T_{b(t)}}{T_{a(t)}-T_{b(t)}},
$$

The similarity variables defined in Equation (7) have been used in Equations (1)-(6). The continuity equation satisfied automatically and the rest of the equations are:

$$
\begin{gathered}
\eta \frac{d^{3} f}{d \eta^{3}}+\frac{d^{2} f}{d \eta^{2}}+\operatorname{Re}(1-\varphi)^{2.5}\left((1-\varphi)+\frac{\rho_{C N T}}{\rho_{f}}\right)\left[f \frac{d^{2} f}{d \eta^{2}}-\left(\frac{d f}{d \eta}\right)^{2}-\frac{S}{2}\left(\frac{d f}{d \eta}+\eta \frac{d^{2} f}{d \eta^{2}}\right)\right]- \\
(1-\varphi)^{2.5} \frac{\sigma_{n f}}{\sigma_{f}} M_{\frac{d f}{d \eta}} \pm(1-\varphi)^{2.5}\left((1-\varphi)+\frac{(\rho \beta)_{C N T}}{(\rho \beta)_{f}}\right) G r \Theta=0 \\
\left(\frac{k_{n f}}{k_{f}}+\frac{4 R d}{6}\right)\left(2 \eta \frac{d^{2} \Theta}{d \eta^{2}}+\frac{d \Theta}{d \eta}\right)+\operatorname{RePr}\left((1-\varphi)+\frac{(\rho c p)_{C N T}}{(\rho c p)_{f}}\right)\left[f \frac{d \Theta}{d \eta}-2 \frac{d f}{d \eta} \Theta-\frac{S}{2}\left(\Theta+\eta \frac{d \Theta}{d \eta}\right)\right]=0 .
\end{gathered}
$$

Using the similarity transformation, the boundary conditions for the flow problem can be written as:

$$
f(1)=\frac{d f(1)}{d \eta}=\Theta(1)=1 \text {, at } \eta=1, \frac{d^{2} f(\beta)}{d \eta^{2}}=\frac{d \Theta(\beta)}{d \eta}=0, f(\beta)=\frac{S \beta}{2} .
$$

where Re is the Reynolds number, $S$ is the unsteadiness parameter, $\operatorname{Pr}$ is the Prandtl number, $R d$ is the Radiation parameter, $M$ is the Magnetic parameter, $G r$ is the Grashof number and are defined as:

$$
\begin{aligned}
& \operatorname{Re}=\frac{c a(t)^{2}}{2 v_{f}}, S=\frac{\alpha}{c}, \operatorname{Pr}=\frac{\left(\mu C_{p}\right)_{f}}{k_{f}}, R d=\frac{4 \sigma_{f} T_{b}}{k^{*} k_{f}}, \\
& M=\frac{\sigma_{f} B_{0}^{2}(t) a(t)^{2}}{4 \mu_{f}}, G r=\frac{g a(t)^{2} \Delta T(\rho \beta)_{f}}{4 W_{w} \mu_{f}} .
\end{aligned}
$$

The pressure distribution term is evaluated from Equation (2) as follows

$$
\begin{aligned}
& \frac{p-p_{b}}{c \mu_{f}}=-\frac{\operatorname{Re}}{\eta}\left((1-\varphi)+\frac{\rho_{C N T}}{\rho_{f}}\right)(1-\varphi)^{2.5} f^{2} \\
& -\left(\eta \operatorname{Re}\left((1-\varphi)+\frac{\rho_{C N T}}{\rho_{f}}\right)(1-\varphi)^{2.5}+2\right) \frac{d f}{d \eta},
\end{aligned}
$$

The velocity $V$ is a function of the nanofluid thickness $\beta$ and is defined as:

$$
-V=\frac{-c a}{\sqrt{\eta(1-\alpha t)}} \frac{d f(\beta)}{d \eta}
$$

The non-dimensional forms of skin friction coefficient and heat transfer rate are defined as [32-34]:

$$
\left(\frac{z \operatorname{Re}}{r(t)}\right) C_{f}=(1-\varphi)^{-2.5} \frac{d^{2} f(1)}{d \eta^{2}}, N u=-2 \frac{k_{n f}}{k_{f}} \frac{d \Theta(1)}{d \eta},
$$

\section{OHAM Solution}

In this section, the non-linear flow models in Equations (8) and (9) has been solved analytically through the Optimal homotopy analysis method (OHAM). This method has a tendency to find 
the solution of nonlinear ordinary differential equations up to 20th-30th order approximation. For this purpose, the BVPh 2.0 package, as mentioned in [44-46], is utilized to obtain the 10th order approximations for which the residual error is minimized. This package was introduced in a renowned book "Homotopy Analysis Method" [44]. The basic theory of this method is to minimize the total average squared residuals and find out the consistent local optimal convergence control parameters. The OHAM BVP 2.0 package has the tendency to obtain the suitable range of the parameters for the proposed problem, as obtained in [46].

The linear operators $\mathrm{L}_{f}$ and $\mathrm{L}_{\Theta}$ are defined as:

$$
\mathrm{L}_{f}=\frac{\partial^{4}}{\partial \eta^{4}} \quad \text { and } \quad \mathrm{L}_{\Theta}=\frac{\partial^{2}}{\partial \eta^{2}}
$$

The general outcomes of the $\mathrm{L}_{f}$ and $\mathrm{L}_{\Theta}$ are:

$$
\mathrm{L}_{f}\left[l_{1}+\left(l_{2}\right) \eta+\left(l_{3}\right) \eta^{2}+\left(l_{4}\right) \eta^{3}\right]=0 \quad \text { and } \quad \mathrm{L}_{\Theta}\left[l_{5}+\left(l_{6}\right) \eta+\left(l_{7}\right) \eta^{2}\right]=0 .
$$

According to the BVPh 2.0 package of OHAM, as explained in [44-46], Equations (8) and (9) are written as

$$
\begin{gathered}
\varepsilon_{m}^{f}=\frac{1}{k+1} \sum_{j=1}^{k}\left[\aleph_{f}\left(\sum_{i=1}^{m} f(\eta)\right)_{\xi=j \delta \xi}\right]^{2}, \\
\varepsilon_{m}^{\Theta}=\frac{1}{k+1} \sum_{j=1}^{k}\left[\aleph_{\Theta}\left(\sum_{i=1}^{m} f(\eta), \sum_{i=1}^{m} \Theta(\eta)\right)_{\xi=j \delta \xi}\right]^{2},
\end{gathered}
$$

According to Liao [35] and Gul and Firdous [36], the total squared residual error is defined by

$$
\varepsilon_{m}^{t}=\varepsilon_{m}^{f}+\varepsilon_{m}^{\Theta} .
$$

The total residual error $\varepsilon_{m}^{t}$ in the form of auxiliary parameters has been exhibited in Figures 2 and 3 for the velocity and temperature profiles respectively. The numerical values of the optimal convergence control constraints $h_{f}=-0.5768, h_{\Theta}=-1.6521$ have been archived in case of the SWCNTs-water while $h_{f}=-0.5801, h_{\Theta}=-2.0121$ have been obtained in the case of MWCNTs-water. To inculcate the accuracy of the obtained results, one can find the required range of the embedding parameters involved in the problem. Due to this importance, the range of the physical constraints involved in the modeled problem has been calculated and presented in Figures 4 and 5 .

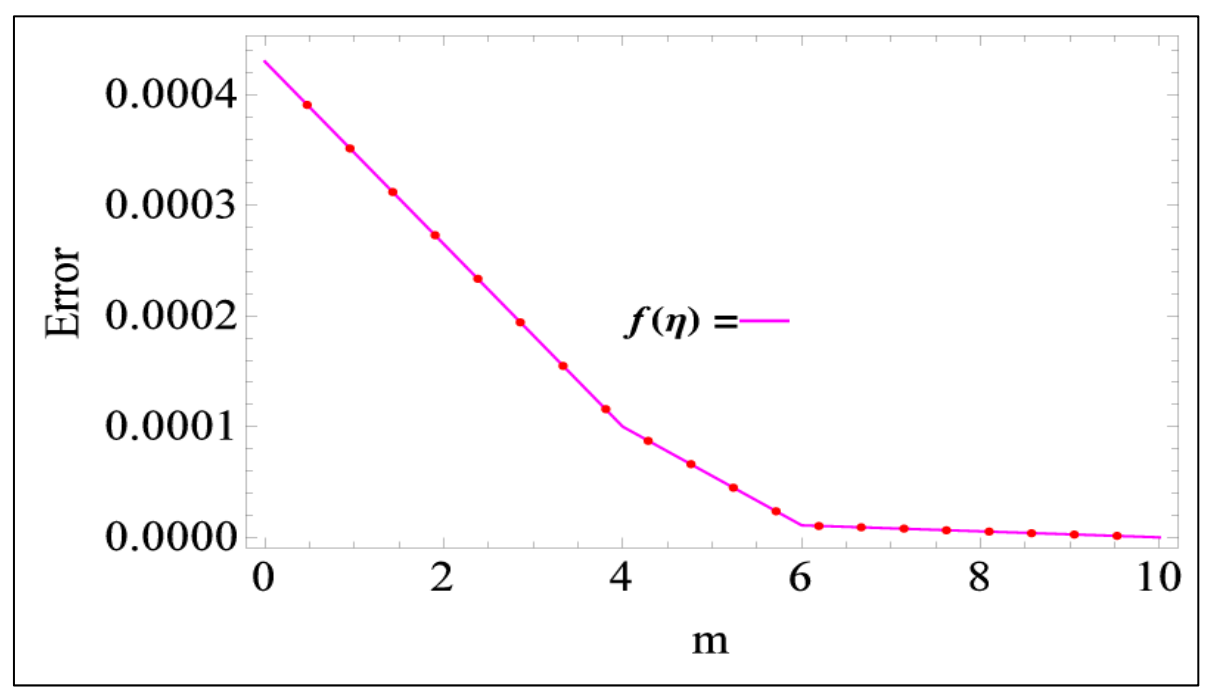

Figure 2. Total residual error in case of CNTs-Water for the velocity profile. 


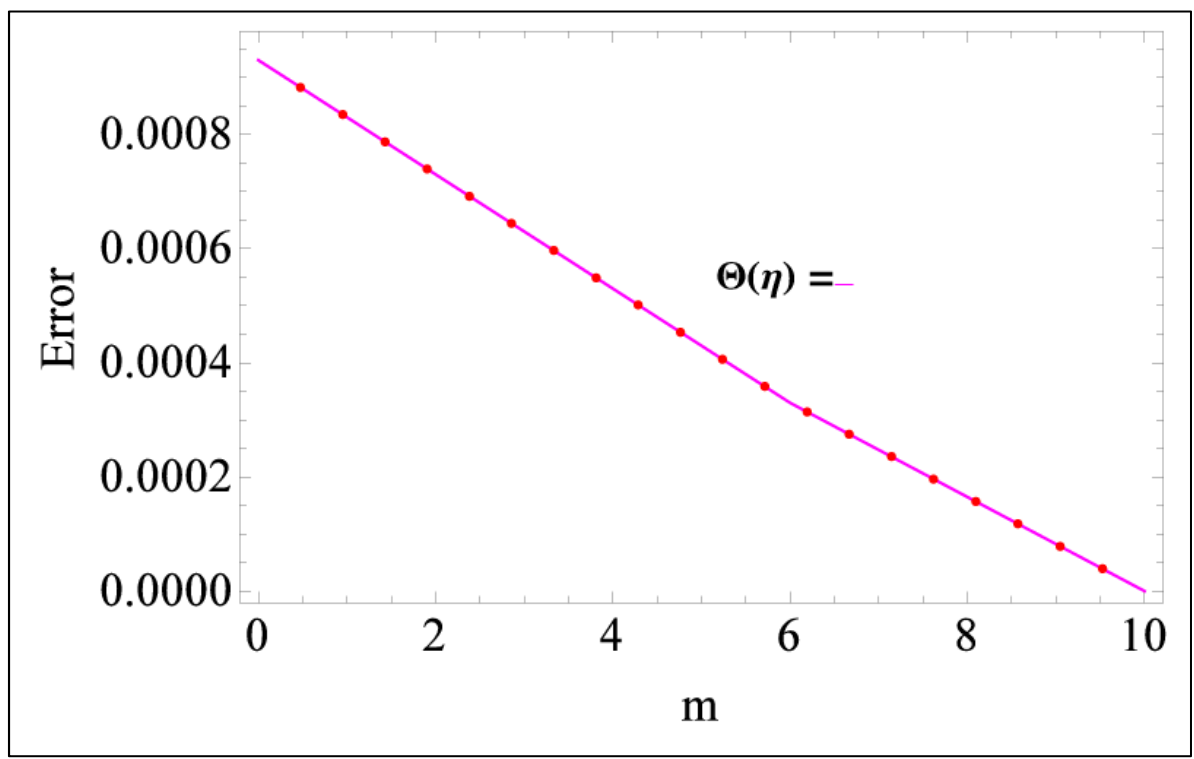

Figure 3. Total residual error in case of CNTs-Water for the temperature profile.

\section{Results and Discussion}

A comprehensive analysis of the unsteady flow of the CNTs-water nanofluid spray over the surface of a vertical cylinder is studied. The dimensionless velocity, temperature and pressure profiles for both (SWCNT's) and (MWCNT's) nanofluids are investigated.

The stepwise detailed discussion of the OHAM method convergence, velocity field, temperature profile, pressure distribution, and spray rate are as follows:

\subsection{Residual Error}

The optimal values of the auxiliary constraints $h_{f}$ and $h_{\Theta}$ are determined to control and stabilize the OHAM solution. The geometry of the problem is depicted in Figure 1. The total residual error is exhibited in Figures 2 and 3 for the dimensionless velocity and temperature fields. They authenticate strong convergence of this method. The numerical values of the optimal convergence control constraints $h_{f}=-0.5768, h_{\Theta}=-1.6521$ have been archived in case of the SWCNTs-water while $h_{f}=-0.5801, h_{\Theta}=-2.0121$ have been obtained in case of MWCNTs-water.

\subsection{Velocity Profile}

The striking features in the sprayed pattern on the surface of a stretching cylinder are the depth of the nano liquid film $\beta$ and the nanoparticle volume fraction $\varphi$ for both types of CNTs.

In the first phase, attention was paid to the impact of the thickness parameter $\beta$, due to its important role during spray coating. The velocity of fluid quickly varies with the variation of liquid film thickness $\beta$. The thin liquid flow moves quickly while the thick liquid comparatively moves slower.

From Figure 4, it is obvious that the velocity declines with larger values of $\beta$. The growing thickness enhances the mass of the nanofluid, therefore, the fluid flow declines. The enhancement of the spray rate and radial velocity $f^{\prime}(\eta)$ is assumed to vary with the thinning liquid film and this effect is clear in the SWCNTs due to its physical properties as compared to the MWCNTs.

The nanoparticle volume fraction $\varphi$ has an important role in the thermal applications. The larger amount of the nanoparticle volume fraction $\varphi$ reduces the internal cohesive forces among the molecules of the liquid and as a result the viscous forces become feeble to stop the flow. Therefore, the larger the value of $\varphi$, the larger will be the radial velocity and this effect is comparatively strong in case of SWCNTs. 


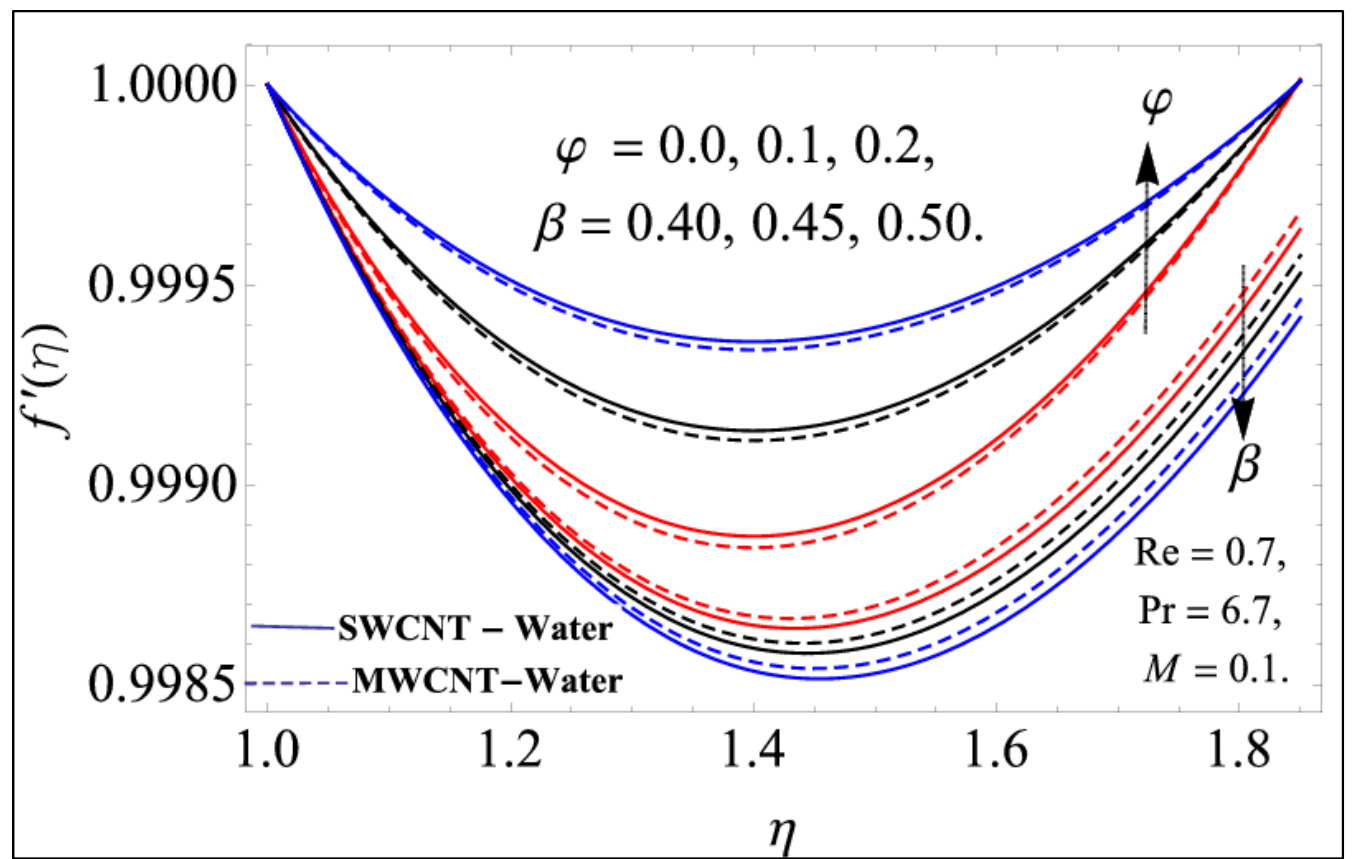

Figure 4. Impact of the nanoparticle volume fraction $\varphi$ and thin film thickness parameter $\beta$ on the velocity field.

The effects of $G r$ and $S$ on the dimensionless velocity are shown in Figure 5. The vertical cylinder is stretched equally in the upper and lower directions. Therefore, the Grashof number $G r$ is treated positive and negative in the momentum boundary layer equation. The radial velocity of the nano liquid film for the larger amount of the Grashof number gradually towards the free surface. While the radial velocity decline using the negative value of $G r$ which shows the opposite impact against the natural convection. The influence of $S$ depicts the change in the fluid velocity and shown in the same Figure 5.

The thickness of the momentum boundary-layer increases for larger values of the parameter $S$ which indicates the decline in the velocity field and this effect is almost the same for both sorts of CNTs.

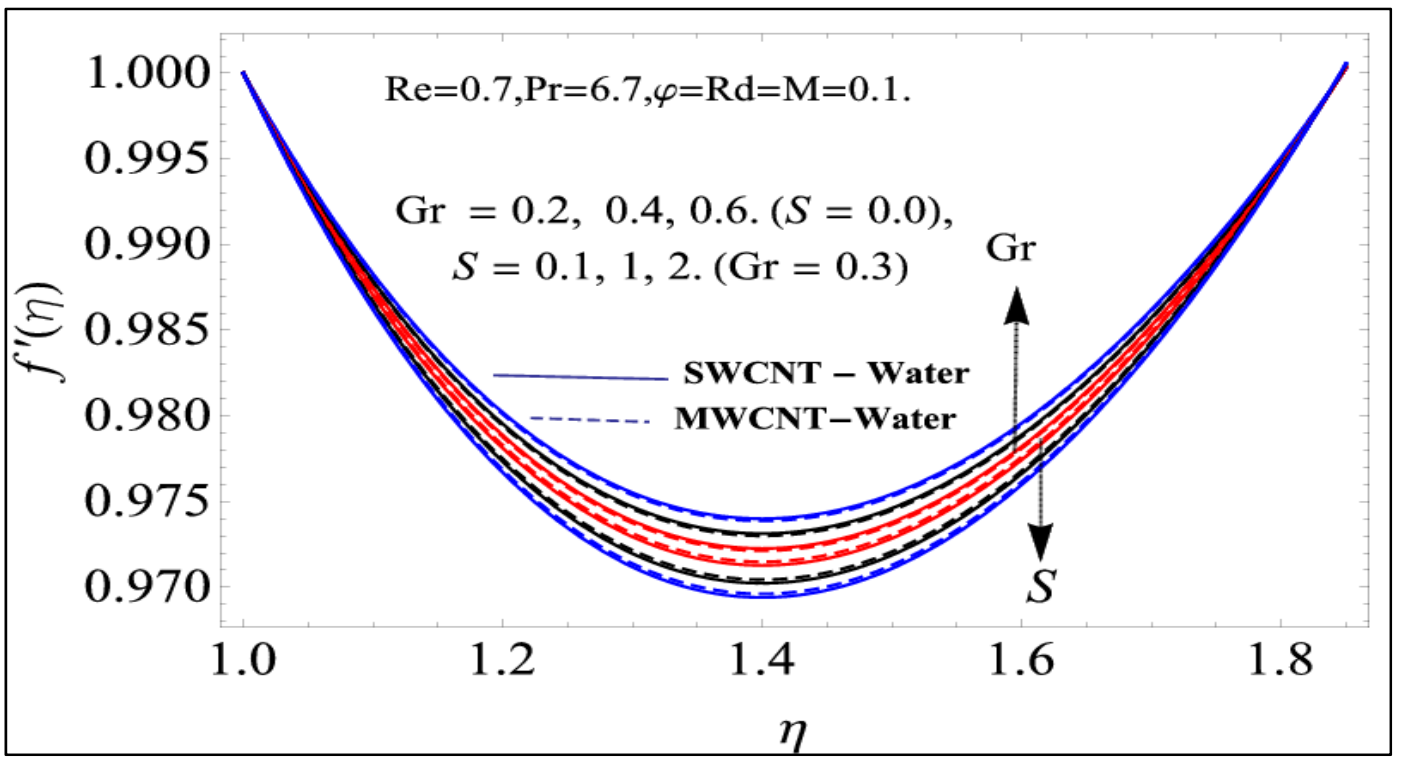

Figure 5. Impact of the Gr \& $S$ on the velocity field. 
The impact of the Reynolds number Re and magnetic parameter $M$ on the dimensionless velocity is presented in Figure 6. It is observed that the radial velocity goes to decline for the larger values of Re. Physically, Re, expresses the ratio among the inertia forces and viscous forces and the larger value of the Re boosted the inertial force. Therefore, the larger amount of Re retards the radial and the motion declines slowly.

Furthermore, the strong inertial forces packed the atoms/molecules of the nano liquid-tightly and do not allow them to flow. The impact of the inertial forces is relatively strong in the SWCNTs. The spray pattern retarded for the higher values of $M$. In fact, the execution of the magnetic field of the spray pattern produces a resistive force called the Lorentz force and this force to produce the retardation in the motion of the fluid. Due to the physical properties of the SWCNTs, this impact is comparatively strong.

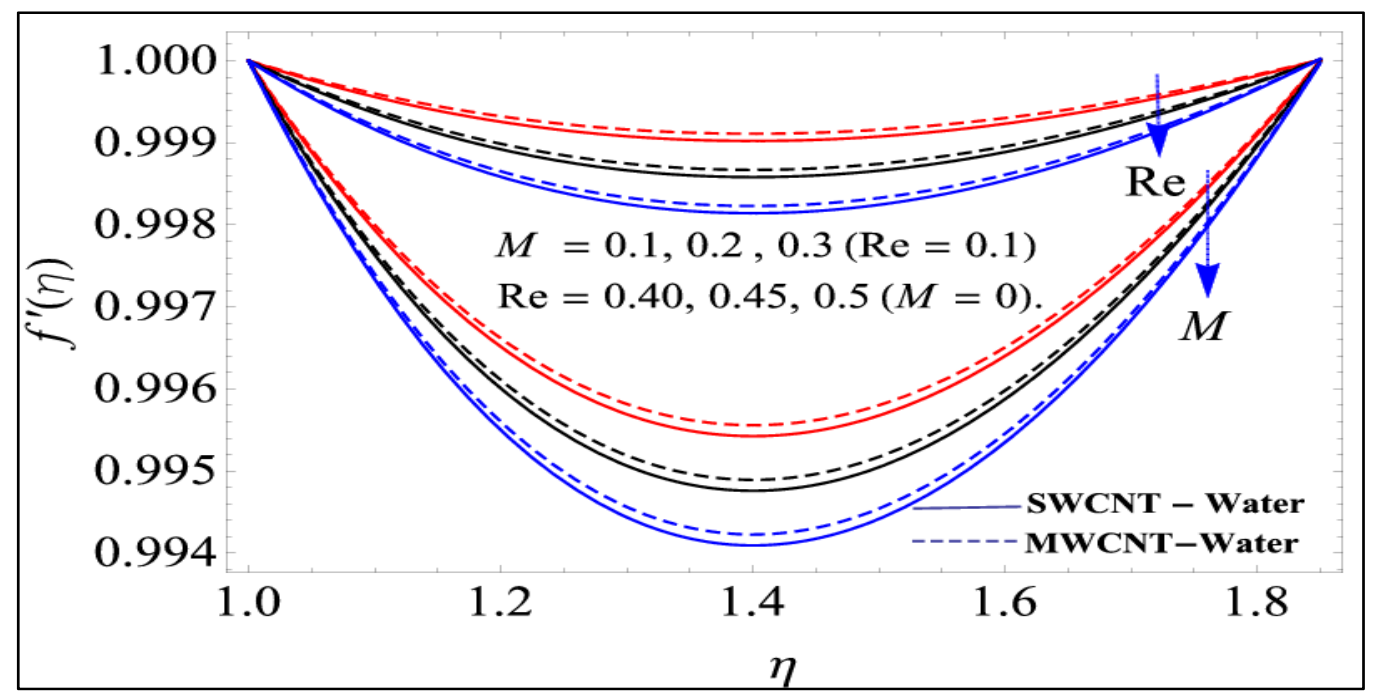

Figure 6. Impact of the $M \&$ Re on the velocity field.

\subsection{Temperature Profile}

The main objective of the current research is the thermal study which has a prominent application in the heating of the cylinder. The carbon nanotubes CNTs plays a vital role to enhance the thermal properties of the surface during spray phenomenon. The thickness $\beta$ of the liquid film has an important role in heat transfer. The temperature distribution decelerates for the larger values of $\beta$ which is demonstrated in Figure 7. The thin liquid is proficient for the transmission of energy while thick liquid depreciates energy transport. Physically, the mass of the fluid rises with the greater quantity of the thick liquid which reduces the dimensionless temperature. The heat can easily penetrate in the thin liquids as compared to the thick liquids. Therefore, the larger quantity of the thickness parameter $\beta$ decelerates the temperature field and this effect is almost the same for both CNTs.

The larger value of $M$ increases the dimensionless temperature as shown in Figure 7. The application of the magnetic field imply that the resistive force generated by the magnetic field, known as the Lorentz force, is responsible for the enhancement of temperature. The transverse magnetic field controls and bounds the boundary layer, whereas the Lorentz force supports the temperature profile; this effect is the same for both CNTs. 


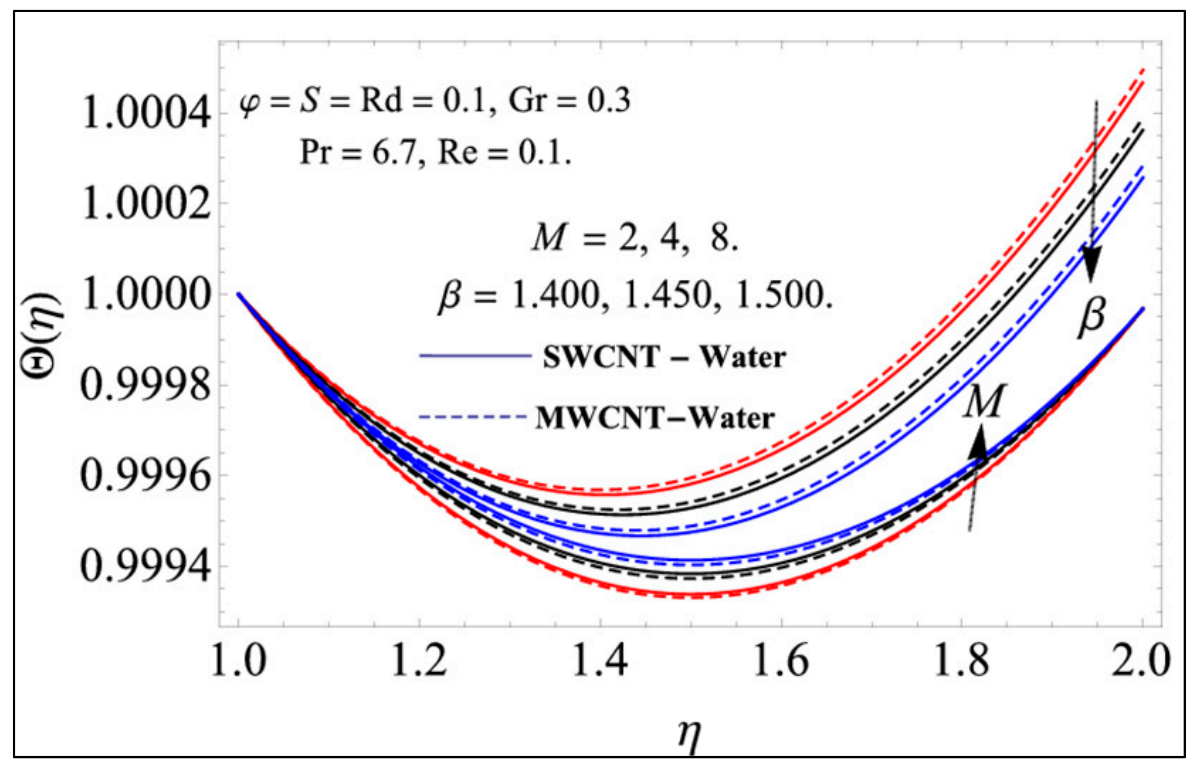

Figure 7. Impact of the $M \& \beta$ on the temperature field.

Figure 8 predicts the effects of the Prandtl number Pr and Reynolds number Re on the dimensionless temperature $\Theta(\eta)$. The maximum cooling is attained with the larger values of $\operatorname{Pr}$ and this influence is hastier for the CNTs. In fact, $\mathrm{Pr}$, is the ratio of momentum diffusivity to thermal diffusivity. The fluids having low $\mathrm{Pr}$, are capable for the higher heat transfer rate. Therefore, the larger value of the Prandtl number diffuses temperature field. Similarly, the temperature distribution depreciates for the larger values of Re, displayed in the Figure 8. The Reynolds number implies that the dominant inertial forces differs the viscous forces. Due to the strong inertial forces, the molecules and atoms of the nano liquid are tightly bounded which requires more energy to collapse them. The decline effect due to the larger value of the Reynolds number is comparatively faster in the SWCNTs.

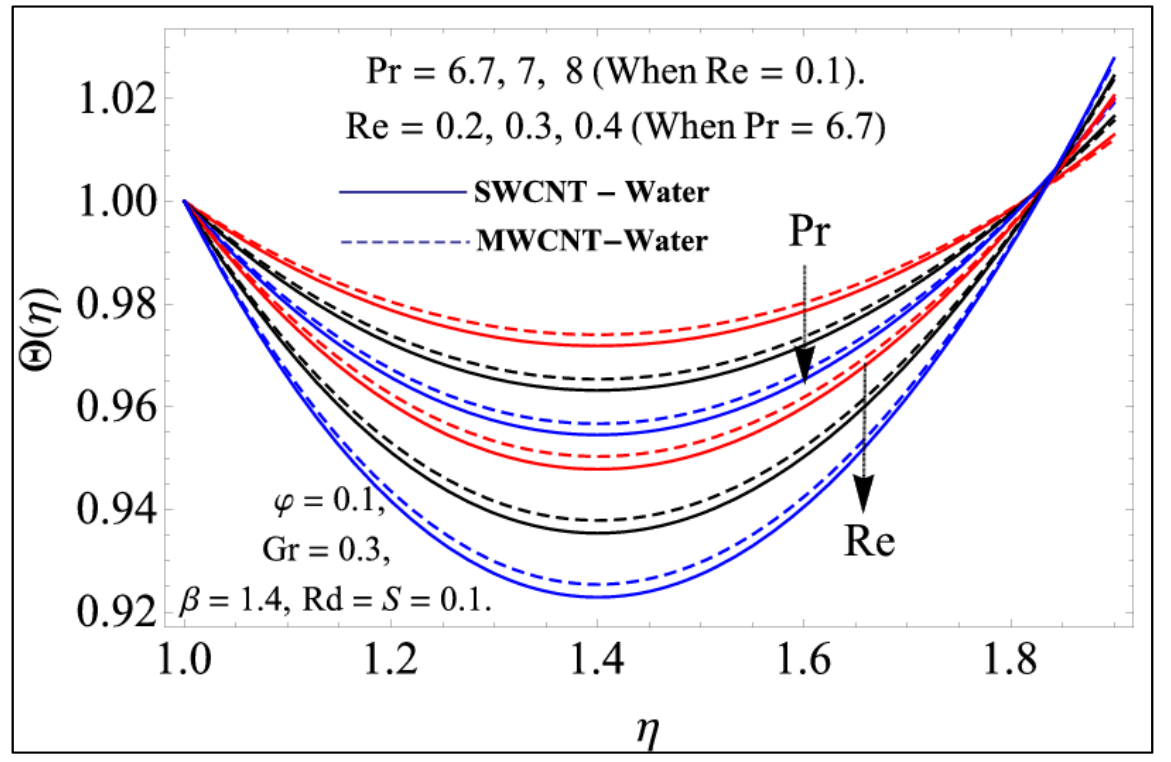

Figure 8. Impact of the $\operatorname{Pr} \& \operatorname{Re}$ on the temperature field.

The impact of the unsteady parameter $S$ and radiation parameter $R d$ on the dimensionless temperature is displayed in Figure 9. The unsteadiness parameter $S$ has the inverse relation to the stretching constraint of the temperature field. Therefore, the larger value of the parameter $S$ declines the temperature field. The larger value of thermal radiation $R_{d}$, enhances the nanofluid temperature. 
Physically, the higher values of the radiation parameter produce a sufficient capacity of heating to the CNTs to enhance the temperature field. Due to excellent physical properties of the SWCNTs, the thermal radiation is more effective in the SWCNTs as compared to the MWCNTs.

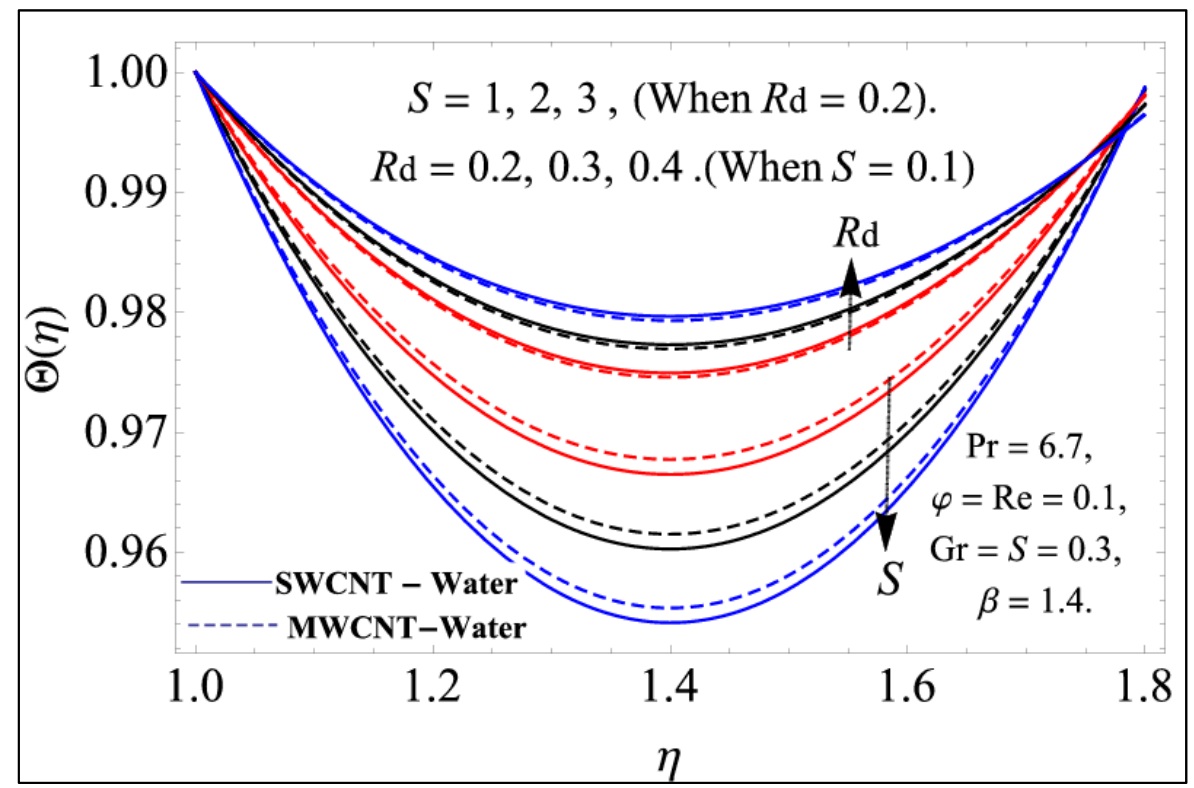

Figure 9. Impact of the $S \& R d$ on the temperature field.

\subsection{Pressure Distribution}

The pressure term has an important factor in the spray pattern. Figure 10 specifies that pressure distribution which increases for the larger values of the thickness parameter $\beta$. Physically, more pressure is required for the thick boundary layer as compared to the thinning liquids during spray phenomenon. The pressure distribution boosts up with the larger thickness parameter $\beta$ and extra power is essential to stun the stress spawned due to the greater thickness of the nano liquid film. This effect is observed relatively strong in the SWCNTs.

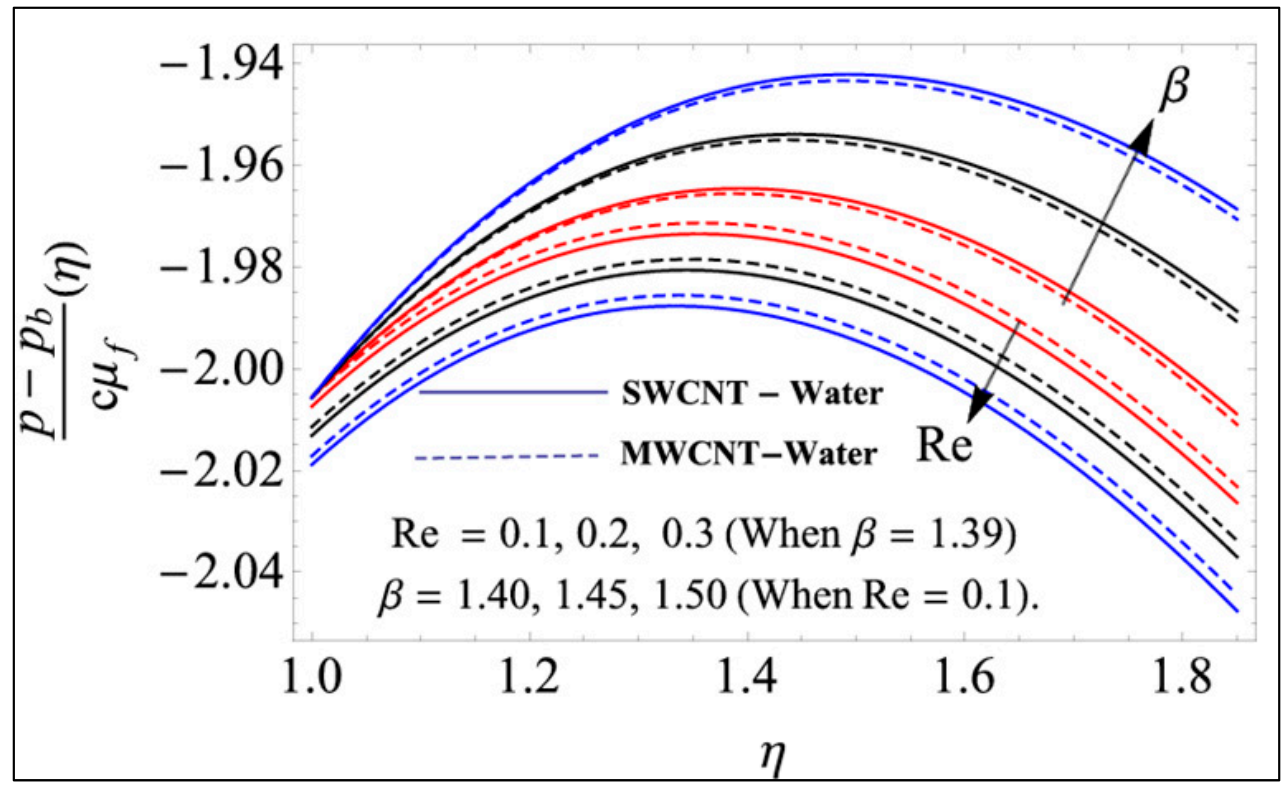

Figure 10. Impact of the $\operatorname{Re} \& \beta$ on the pressure distribution. 
The greater values of the Reynolds number Re decline the pressure term as it is illustrated in Figure 10. Due to the inertial forces, the pressure inevitably goes at the lowest rate in the broad way of motion. The particles of the nano liquid are tightly packed and more pressure is required for the fluid motion.

The impact of the natural convection parameter $G r$ on the pressure distribution is displayed in Figure 11 for positive and negative values. The pressure distribution increases with the positive values of the Grashof number $\mathrm{Gr}$ and decline with the negative values of $\mathrm{Gr}$. Since the vertical cylinder stretches equally up and down, the natural convection is observed in the same pattern. In the upward direction $G r<0$ and during downward direction $G r>0$. The larger values of $G r$ enhances the pressure distribution while its negative value causes to decrease the fluid motion and pressure distribution as well.

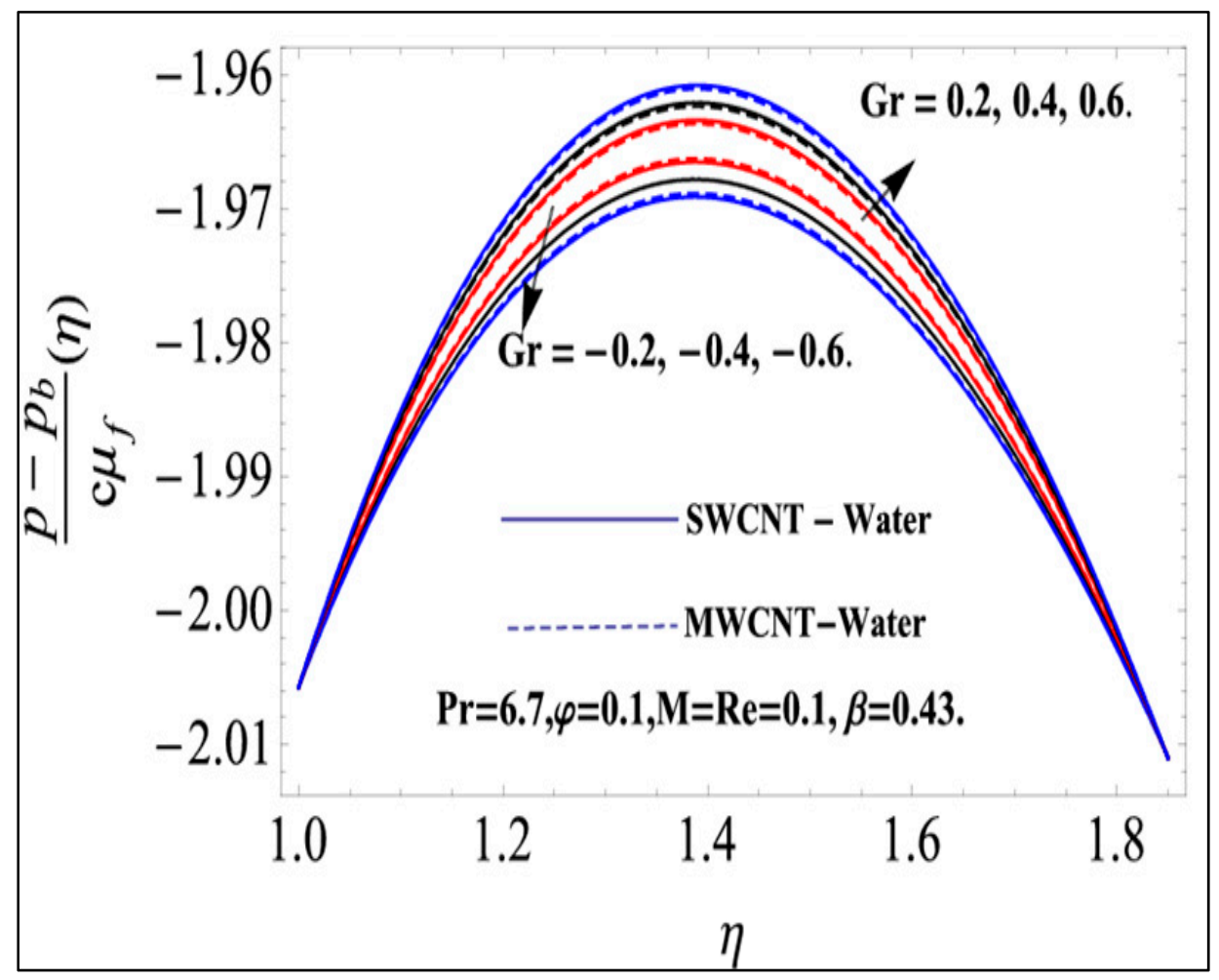

Figure 11. Impact of the positive and negative values of the $G r$ on the pressure distribution.

\subsection{Spray Distribution}

The spray rate or spray distribution is the essential part of the painting phenomenon and the uniform spray distribution is the important factor of this manifestation. The vertical and stretching cylinder is sprayed by a nanofluid for the thermal applications and protecting the paint.

Figure 12 displays the mass flux $m_{1}(\beta)$ which is a function of the thickness parameter $\beta$. It is obvious that the mass flux enhances the size of the film $\beta$. For the constant spray rate, the deposition velocity needs to be uniform and much-closed impact observed for both sorts of CNTs. 


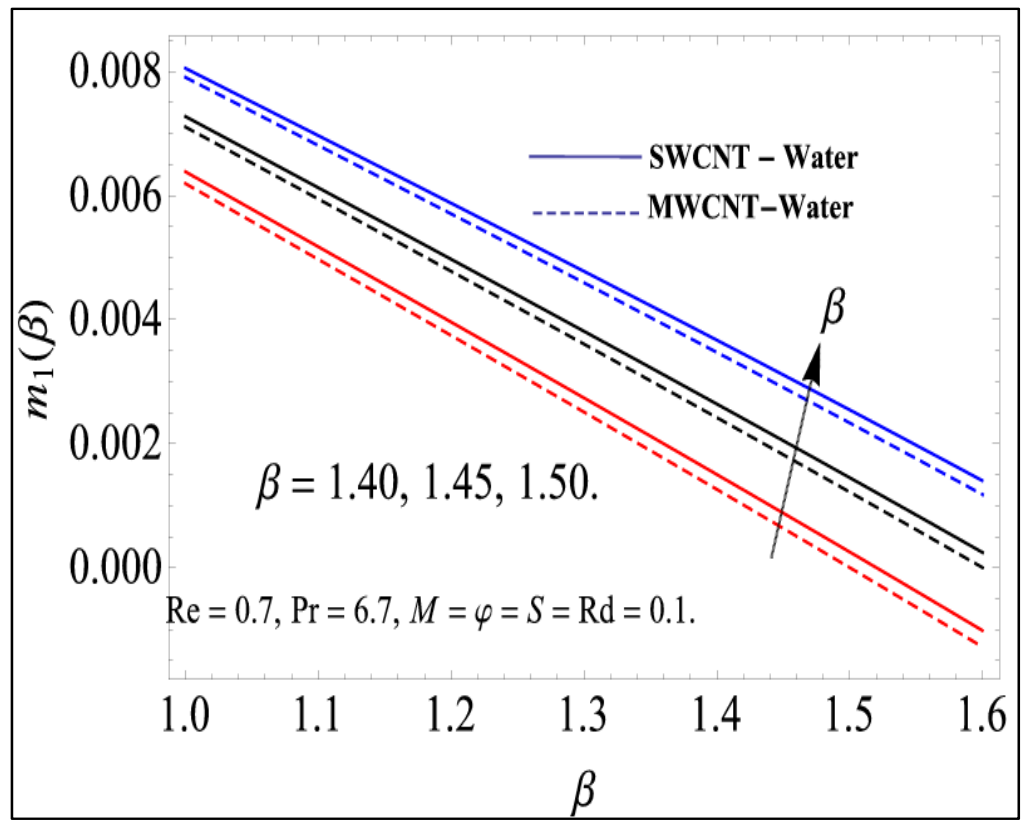

Figure 12. The impact of the thickness parameter $\beta$ on the mass flux $m_{1}(\beta)$.

The impact of the normalized spray rate $m_{2}(\beta)$, which is the function of the film size $\beta$ is illustrated in Figure 13. The normalized spray rate $m_{2}(\beta)$ is increasing with the larger values of the thickness parameter $\beta$. In fact, the thinning liquids need low spray rate and the normalized spray rate rises with thicker liquids. Again, this effect is almost the same for the SWCNTs and MWCNTs.

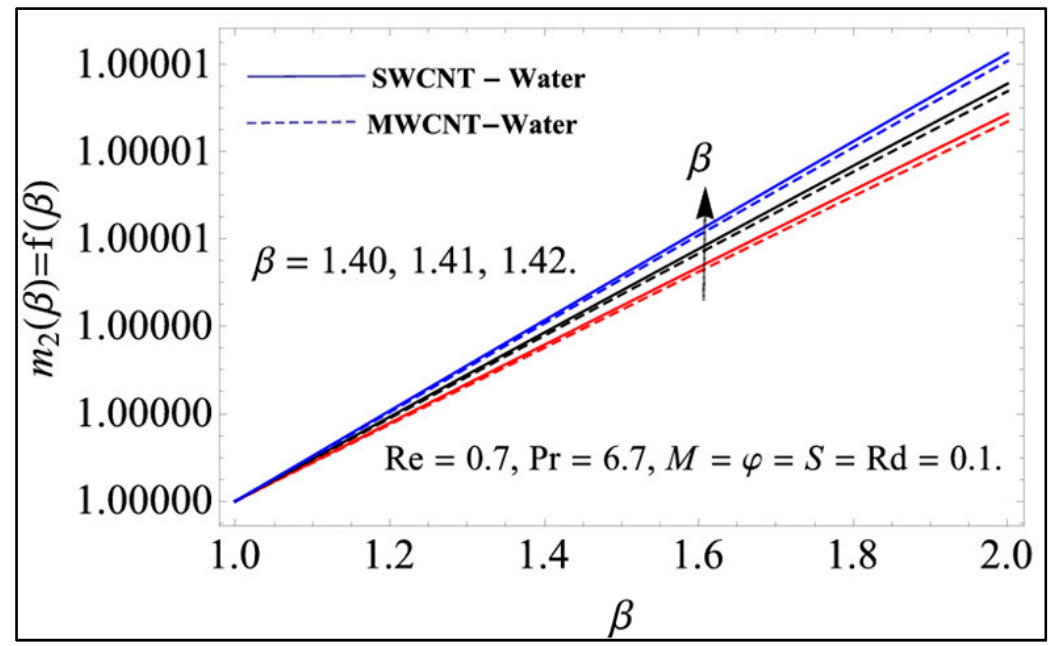

Figure 13. The impact of the thickness $\beta$ on the rate of spray $m_{2}(\beta)$.

\subsection{Skin Friction and Nusselt Number}

Table 1 indicates the thermophysical properties of the base liquid and solid carbon nanotubes. The residual errors for SWCNTs/MWCNTs-Water are presented in Table 2. The influence of the unsteadiness constraint $S$, Reynolds number Re and Grashof number $G r$ versus the local skin friction are scrutinized in Table 3. The large values of $S$ and Re raises the skin friction coefficient $f^{\prime \prime}(1)$. In fact, the larger values of these parameters enhance the friction force to increase the skin friction. The larger values of the Grashof number $G r$ reduces the friction force and therefore, the skin friction decline. These effects are comparatively stronger in the case of the SWCNTs.

The influence of the unsteadiness parameter S, Reynolds number Re, and Grashof number Gr on the heat transfer rate (Nusselt number), is scrutinized in Table 4. 
The larger values of the parameters $S$, Re and $G r$ enhances the heat transfer rate. The effects of these parameters are more effective in the case of SWCNTs.

Table 1. The thermophysical properties of CNTs and the base fluid water.

\begin{tabular}{|c|c|c|c|c|}
\hline \multicolumn{2}{|c|}{ Model } & $\rho\left(\mathrm{kg} / \mathrm{m}^{3}\right)$ & $C_{p}(\mathrm{~kJ} / \mathrm{kg} \cdot \mathrm{C})$ & $k\left(W m^{-1} k^{-1}\right)$ \\
\hline \multicolumn{2}{|c|}{ Water (W) } & 997.1 & 4179 & 0.613 \\
\hline \multirow{2}{*}{ Nanoparticles } & SWCNT & 2600 & 425 & 6600 \\
\hline & MWCNT & 1600 & 796 & 3000 \\
\hline
\end{tabular}

Table 2. Individual averaged squared residual errors for SWCNTs/MWCNTs-Water when $\beta=$ 1.1, $\operatorname{Pr}=6.7, \operatorname{Rd}=M=S=\operatorname{Re}=G r=0.1, \varphi=0.01$.

\begin{tabular}{ccccc}
\hline$m$ & $\varepsilon_{m}^{f}$ SWCNTs & $\varepsilon_{m}^{f}$ MWCNTs & $\varepsilon_{m}^{\Theta}$ SWCNTs & $\varepsilon_{m}^{\Theta}$ MWCNTs \\
\hline 2 & $4.86 \times 10^{-2}$ & $3.21 \times 10^{-2}$ & $3.81 \times 10^{-3}$ & $2.72 \times 10^{-3}$ \\
\hline 6 & $4.21 \times 10^{-4}$ & $3.53 \times 10^{-4}$ & $4.85 \times 10^{-5}$ & $3.24 \times 10^{-5}$ \\
\hline 10 & $6.18 \times 10^{-6}$ & $5.89 \times 10^{-6}$ & $2.03 \times 10^{-7}$ & $1.55 \times 10^{-7}$ \\
\hline 12 & $8.71 \times 10^{-7}$ & $7.71 \times 10^{-7}$ & $7.75 \times 10^{-8}$ & $6.61 \times 10^{-8}$ \\
\hline
\end{tabular}

Table 3. Exhibits the Numerical values for skin friction coefficient for different physical parameters when $\beta=1.1, \operatorname{Pr}=6.7, \operatorname{Rd}=M=0.1, \varphi=0.01$.

\begin{tabular}{ccccc}
\hline$S$ & Re & Gr & $\begin{array}{c}f^{\prime \prime}(1) \\
\text { MWCNTs }\end{array}$ & $\begin{array}{c}f^{\prime \prime}(1) \\
\text { SWCNTs }\end{array}$ \\
\hline 0.7 & 0.8 & 0.4 & 0.110882 & 0.112002 \\
\hline 0.8 & - & - & 0.115651 & 0.120112 \\
\hline 0.9 & - & - & 0.120394 & 0.129546 \\
\hline- & 0.9 & - & 0.121308 & 0.130145 \\
\hline- & 1.0 & - & 0.131821 & 0.139887 \\
\hline- & - & 0.5 & 0.109913 & 0.112334 \\
\hline- & - & 0.7 & 0.108945 & 0.110059 \\
\hline
\end{tabular}

Table 4. Exhibits the Numerical values of local Nusselt number for different physical parameters, when $\beta=1.1, \mathrm{G}_{r}=0.4, \varphi=0.01, \mathrm{~h}=-0.7$.

\begin{tabular}{ccccc}
\hline $\boldsymbol{S}$ & $\boldsymbol{R}$ & $\boldsymbol{P r}$ & $\begin{array}{c}-\boldsymbol{\theta}^{\prime}(1) \\
\text { MWCNTs }\end{array}$ & $\begin{array}{c}-\boldsymbol{\theta}^{\prime}(1) \\
\text { SWCNTs }\end{array}$ \\
\hline 0.7 & 0.8 & 0.7 & 0.703065 & 0.71462 \\
\hline 0.8 & - & - & 0.712599 & 0.723478 \\
\hline 0.9 & - & - & 0.721968 & 0.731021 \\
\hline- & 0.9 & - & 0.797565 & 0.809235 \\
\hline- & 1.0 & - & 0.893586 & 0.90256 \\
\hline- & - & 0.8 & 0.811450 & 0.82941 \\
\hline- & - & 0.9 & 0.921894 & 0.932464 \\
\hline
\end{tabular}




\section{Conclusions}

The surface of a vertical stretching cylinder was sprayed by nanofluid for the thermal applications. Water was used as a base solvent for the diffusion of the CNTs. Both SWCNTs and MWCNTs were used for the spray over the stretching surface. The solution of the modeled nonlinear differential equations was obtained through OHAM. The absolute residual error was calculated for the velocity and temperature fields. The range of the embedded parameters was obtained for the stable convergence. The parallel and normalized spray rates have also been calculated for the uniformity of spray phenomenon. The pressure distribution is also necessary for the uniform spray coating and has been observed in this study. It has been concluded that the SWCNTs are comparatively more efficient in the enhancement of heat transfer rate as compared to the MWCNTs. In fact, the thermophysical properties of SWCNTs are found to be stronger than the MWCNTs.

The obtained outputs are deliberated as follow.

- The increasing thickness parameter $\beta$ reduces the flow motion. This effect is more efficient in the case of the SWCNTs as compared to the MWCNTs.

- The larger values of $\varphi$ reduce the intermolecular forces which boosts the fluid motion.

- The higher values of the thermal radiation parameter $R_{d}$ increase the dimensionless temperature.

- The larger values of $M$ raise the temperature distribution and decline the fluid motion. This effect is strong in the case of the SWCNTs.

Author Contributions: T.G. and M.T.; conceptualization, R.B. and W.A.K.; methodology, I.K.; software, K.S.N. and W.A.K.; validation, T.G. and R.B.; formal analysis, I.K.; W.A.K.; investigation, T.G.; I.K.; and W.A.K.; writing original draft preparation, T.G.; and M.T.; writing-review and editing.

Funding: This research received no external funding.

Conflicts of Interest: The authors declare that they have no conflict of interest.

\section{Nomenclature}

\begin{tabular}{|c|c|c|}
\hline Name & Significances & Definition \\
\hline Grashof number & $\frac{\text { Buoyancy force }}{\text { viscous force }}$ & $G r=\frac{g \beta|\Delta| T L^{3} \rho^{2}}{\mu^{2}}$ \\
\hline Nusselt number & $\frac{\text { Convection heat transfer }}{\text { Conduction heat transfer }}$ & $N u=\frac{L h}{k}$ \\
\hline Prandtl number & $\frac{\text { vicous diffusion }}{\text { Thermal diffusion }}$ & $\operatorname{Pr}=\frac{v}{\alpha}=\frac{\mu C_{p}}{k}$ \\
\hline Rayleigh number & $\frac{\text { Buoyancy force }}{\text { viscous force }}$ & $R=\frac{g \beta|\Delta| T L^{3} \rho^{2} C_{p}}{k \mu^{2}}$ \\
\hline Reynolds number & $\frac{\text { Inertial force }}{\text { viscous force }}$ & $R_{e}=\frac{\rho V L}{\mu}=\frac{V L}{v}$ \\
\hline Specfic heat ratio & $\frac{\text { entropy }}{\text { internal enegry }}$ & $k=\frac{C_{p}}{C_{v}}$ \\
\hline Symbols' used & & \\
\hline Abbreviations & \multicolumn{2}{|l|}{ Symbol } \\
\hline$B_{0}$ & \multicolumn{2}{|c|}{ Magnetic field strength $\mathrm{NmA}^{-1}$} \\
\hline$f$ & \multicolumn{2}{|c|}{ Dimensional velocity profiles } \\
\hline$T$ & \multicolumn{2}{|l|}{ Fluid temperature $(\mathrm{K})$} \\
\hline$T_{w}$ & \multicolumn{2}{|c|}{ Cylinder surface temperature $(\mathrm{K})$} \\
\hline$T_{\delta}$ & \multicolumn{2}{|c|}{ Free surface temperature $(\mathrm{K})$} \\
\hline$M$ & \multicolumn{2}{|l|}{ Magnetic parameter } \\
\hline$p$ & \multicolumn{2}{|l|}{ Pressure distribution } \\
\hline$c$ & \multicolumn{2}{|l|}{ Stretching parameter } \\
\hline$C_{f}$ & \multicolumn{2}{|c|}{ Skin friction coefficient } \\
\hline$W_{w}$ & \multicolumn{2}{|l|}{ Stretching velocity } \\
\hline$U_{u}$ & \multicolumn{2}{|c|}{ Suction/injection speed } \\
\hline$C_{p f}$ & \multicolumn{2}{|c|}{ Specific heat of base fluid $(\mathrm{J} / \mathrm{kg} \mathrm{K})$} \\
\hline
\end{tabular}




$\begin{array}{ll}k_{n f} & \text { Thermal conductivity }\left(\mathrm{W} \mathrm{m}^{-1} \mathrm{~K}^{-1}\right) \\ \mathrm{S} & \text { Unsteady parameter } \\ \text { Greeks symbols } & \\ \mu_{n f} & \text { Dynamic viscosity of nanofluid }(\mathrm{mPa}) \\ \beta_{n f} & \text { Thermal expansion coefficient } \\ \rho_{n f} & \text { Nanofluid density }\left(\mathrm{kg} \mathrm{m}^{3}\right) \\ \mu_{n f} & \text { Kinematic Viscosity } \\ \eta & \text { Similarity variable } \\ \varphi & \text { Dimensional heat profiles } \\ \sigma_{n f} & \text { Electrical conductivity } \\ \beta & \text { Non-dimensional thickness } \\ \tau & \text { Surface shear stress } \\ h & \text { Auxiliary constant }\end{array}$

Appendix A

\begin{tabular}{cc}
\hline$\frac{k_{n f}}{k_{f}}=\frac{1-\varphi+2\left(\frac{k_{C N T}}{k_{C N T}-k_{f}} \ln \frac{{ }^{k_{C N T}+k_{f}}}{2 k_{f}}\right) \varphi}{1-\varphi+2\left(\frac{k_{f}}{k_{C N T}-k_{f}} \ln \frac{{ }^{k_{C N T}+k_{f}}}{2 k_{f}}\right) \varphi}$. & Xue [20] \\
\hline $\begin{array}{c}\rho_{n f}=\rho_{f}(1-\varphi)+\varphi \rho_{C N T},\left(\rho C_{p}\right)_{n f}=\left(\rho C_{p}\right)_{f}(1-\varphi)+\left(\rho C_{p}\right)_{C N T} \varphi, \\
\sigma_{n f}=\sigma_{f}\left(\frac{1+3(\sigma-1) \varphi}{(\sigma+2)-(\sigma-1) \varphi}\right), \alpha_{n f}=\frac{\mu_{n f}}{\left(\rho c_{p}\right)_{n f}}, \mu_{n f}=\frac{\mu_{f}}{(1-\varphi)^{2.5} .}\end{array}$ & Thermophysical Properties \\
\hline$\beta=\left(\frac{b}{a \sqrt{(1-\alpha t)}}\right)^{2} \Rightarrow \frac{d b}{d t}=\frac{-a \alpha}{2} \sqrt{\frac{\beta}{(1-\alpha t)}}$, & Depth of the thin liquid \\
\hline$m_{1}=\frac{2 \pi b(t) c a(t)}{\sqrt{\eta(1-\alpha t)}} \frac{d f(\beta)}{d \eta}=V 2 \pi b(t)$, & Mass flux \\
\hline$m_{2}=\frac{m_{1}}{2 \pi c a^{2}(t)}=\frac{m_{1}}{4 \pi v_{f} \operatorname{Re}}=f(\beta)$, & Normalized mass flux \\
\hline
\end{tabular}

\section{References}

1. Choi, S.; Eastman, J. Enhancing Thermal Conductivity of Fluids with Nanoparticles. In Proceedings of the ASME International Mechanic Engineering Congress and Exposition, San Francisco, CA, USA, 12-17 November 1995.

2. Iijima, S. Helical microtubules of graphitic carbon. Nature 1991, 354, 56-58. [CrossRef]

3. Oberlin, A.; Endo, M.; Koyama, T. Filamentous growth of carbon through benzene decomposition. J. Cryst. Growth 1976, 32, 335-349. [CrossRef]

4. Iijima, S.; Ichihashi, T. Single-shell carbon nanotubes of $1 \mathrm{~nm}$ diameter. Nature 1993, 363, 603-605. [CrossRef]

5. Bethune, D.S.; Kiang, C.H.; Devries, M.S.; Gorman, G.; Savoy, R.; Vazquez, J.; Beyers, R. Cobalt-catalysed growth of carbon nanotubes with single-atomic-layer walls. Nature 1993, 363, 605-607. [CrossRef]

6. Volder, M.D.; Tawfick, S.; Baughman, R.; Hart, A. Carbon nanotubes: Present and future commercial applications. Science 2013, 339, 535-539. [CrossRef]

7. Terrones, M. Synthesis, properties, and applications of carbon nanotubes: Science, and technology of the twenty-first century. Annu. Rev. Mater. Res. 2003, 33, 491-501. [CrossRef]

8. Zhang, J.; Liu, X. Dispersion performance of carbon nanotubes on ultra-light foamed concrete. Processes 2018, 6, 194. [CrossRef]

9. Murshed, S.M.S.; de Castro, C.A.N.; Loureno, M.J.V.; Lopes, M.L.M.; Santos, F.J.V. A review of boiling and convective heat transfer with nanofluids. Renew. Sustain. Energy Rev. 2011, 15. [CrossRef]

10. Murshed, S.M.S.; Leong, K.C.; Yang, C. Thermophysical and electrokinetic properties of nanofluids a critical review. Appl. Therm. Eng. 2008, 28, 2109-2125. [CrossRef]

11. Kamali, R.; Binesh, A.R. Numerical investigation of heat transfer enhancement using carbon nanotube-based nonnewtonian nanofluids. Int. Commun. Heat Mass. Transf. 2010, 37, 1153-1157. [CrossRef]

12. Pal, H.; Sharma, V. Effect of sintering on mechanical and electrical properties of carbon nanotube-based silver nanocomposites. Indian J. Phys. 2015, 89, 217-224. [CrossRef] 
13. Domairry, G.; Aziz, A. Approximate analysis of MHD squeeze flow between two parallel disks with suction or injection by homotopy perturbation method. Math. Probl. Eng. 2009, 1-19. [CrossRef]

14. Rashidi, M.; Ganesh, M.; Vishnu, N.; Hakeem, A.; Ganga, B.; Lorenzini, G. Influences of an effective Prandtl number model on nano boundary layer flow of $\mathrm{Al}_{2} \mathrm{O}_{3}-\mathrm{H}_{2} \mathrm{O}$ and $\mathrm{Al}_{2} \mathrm{O}_{3}-\mathrm{C}_{2} \mathrm{H}_{6} \mathrm{O}_{2}$ over a vertical stretching sheet. Int. J. Heat Mass. Transf. 2016, 98, 616-623. [CrossRef]

15. Haq, R.U.; Shahzad, F.; Al-Mdallal, Q.M. MHD pulsatile flow of engine oil based carbon nanotubes between two concentric cylinders. Results Phys. 2017, 7, 57-68. [CrossRef]

16. Hayat, T.; Kiran, A.; Imtiaz, M.; Alsaedi, A. Unsteady flow of carbon nanotubes with chemical reaction and Cattaneo-christov heat flux model. Results Phys. 2017, 7, 823-831. [CrossRef]

17. Hwang, Y.; Ahn, Y.; Shin, H.; Lee, C.; Kim, G.; Park, H.; Lee, J. Investigation on characteristics of thermal conductivity enhancement of nanofluids. Curr. Appl. Phys. 2006, 6, 1068-1071. [CrossRef]

18. Gohar, K.; Taza, G.; Waris, K.; Muhammad, S.; Muhammad, K.; Ebenezer, B. MWCNTs/SWCNTs nanofluid thin film flow over a nonlinear extending disc: OHAM solution. J. Therm. Sci. 2019, 28, 115-122. [CrossRef]

19. Fourier, J.B.J. Theorie Analytique de la Chaleur; F. Didot: Paris, France, 2018.

20. Cattaneo, C. Sulla Conduzione del Calore, Atti Semin; Mat Fis Uni Modena Reggio Emilia; Springer: Berlin/Heidelberg, Germany, 1948.

21. Walvekar, R.; Faris, I.A.; Khalid, M. The thermal conductivity of carbon nanotubes—Experimental and theoretical studies. Heat Transf. Asian Res. 2012, 14, 145-163. [CrossRef]

22. Maxwell, J.C. A Treatise on Electricity Magnetism, 2nd ed.; Clarendon Press: Oxford, UK, 1881.

23. Jaffery, D.J. Conduction through a random suspension of spheres. Proc. R. Soc. Lond. A Math. Phys. Sci. 1973, 335, 335-336.

24. Davis, R. The effective thermal conductivity of a composite material with spherical inclusions. Int. J. Thermophys. 1986, 7, 609-620. [CrossRef]

25. Lu, S.; Lin, H. Effective conductivity of composites containing aligned spherical inclusions of finite conductivity. J. Appl. Phys. 1996, 79, 6761-6769. [CrossRef]

26. Hamilton, R.I.; Crosser, O.K. Thermal conductivity of heterogeneous two-component systems. Ind. Eng. Chem. Fundam. 1962, 1, 187-191. [CrossRef]

27. Xue, Q. Model for thermal conductivity of carbon nanotube-based composites. Phys. B Condens. Matter 2005, 368, 302-307. [CrossRef]

28. Khan, Y.; Wua, Q.; Faraz, N.; Yildirim, A. The effects of variable viscosity and thermal conductivity on a thin film flow over a shrinking/stretching sheet. Comput. Math. Appl. 2011, 61, 3391-3399. [CrossRef]

29. Aziz, R.C.; Hashim, I.; Alomari, A.K. Thin film flow and heat transfer on an unsteady stretching sheet with internal heating. Meccanica 2011, 46, 349-357. [CrossRef]

30. Qasim, M.; Khan, Z.H.; Lopez, R.J.; Khan, W.A. Heat and mass transfer in nanofluid over an unsteady stretching sheet using Buongiorno's model. Eur. Phys. J. Plus 2016, 131, 1-16. [CrossRef]

31. Wang, C.Y. Liquid film sprayed on a stretching cylinder. Chem. Eng. Commun. 2006, 193, 869-878. [CrossRef]

32. Khan, N.S.; Gul, T.; Islam, S.; Khan, I.; Alqahtani, A.M.; Alshomrani, A.S. Magnetohydrodynamic nano liquid thin film sprayed on a stretching cylinder with heat transfer. Appl. Sci. 2017, 7, 271. [CrossRef]

33. Taza, G.; Saleem, N.; Saeed, I.; Zahir, S.; Muhammad, K. Effective Prandtl number model influences on the $\mathrm{YAl}_{2} \mathrm{O}_{3}-\mathrm{H}_{2} \mathrm{O}$ ) and $\mathrm{YAl}_{2} \mathrm{O}_{3}-\mathrm{C}_{2} \mathrm{H}_{6} \mathrm{O}_{2}$ nanofluids spray along a stretching cylinder. Arab. J. Sci. Eng. 2018, 44, 16. [CrossRef]

34. Alshomrani, A.S.; Gul, T. A convective study of $\mathrm{Al}_{2} \mathrm{O}_{3}-\mathrm{H}_{2} \mathrm{O}$ and $\mathrm{Cu}-\mathrm{H}_{2} \mathrm{O}$ nano-liquid films sprayed over a stretching cylinder with viscous dissipation. Eur. Phys. J. Plus 2017, 132, 495-512. [CrossRef]

35. Loganathan, P.; Vimala, C. Unsteady flow of nanofluids past a vertical flat plate with leading-edge accretion or ablation. Indian J. Phys. 2014, 88, 855-859. [CrossRef]

36. Liao, S.J. On the analytic solution of magnetohydrodynamic flows of non-Newtonian fluids over a stretching sheet. J. Fluid Mech. 2003, 488, 189-212. [CrossRef]

37. Liao, S.J. An explicit, totally analytic approximation of Blasius viscous flow problems. Int. J. Non-Linear Mech. 1999, 34, 759-778. [CrossRef]

38. Hayat, T.; Saif, R.S.; Ellahi, R.; Taseer, M.Y.R.; Ahmad, B. Numerical study for Darcy-Forchheimer flow due to a curved stretching surface with Cattaneo-Christov heat flux and homogeneous-heterogeneous reactions. Results Phys. 2017, 7, 28862-28892. [CrossRef] 
39. Hayat, T.; Saif, R.S.; Ellahi, R.; Taseer, M.Y.R.; Alsaedi, A. Simultaneous effects of melting heat and internal heat generation in stagnation point flow of Jeffrey fluid towards a nonlinear stretching surface with variable thickness. Int. J. Therm. Sci. 2018, 132, 344-354. [CrossRef]

40. Shehzad, N.; Zeeshan, A.; Ellahi, R.; Vafai, K. Convective heat transfer of nanofluid in a wavy channel: Buongiorno's mathematical model. J. Mol. Liq. 2016, 222, 446-455. [CrossRef]

41. Ellahi, R.; Riaz, A. Analytical solutions for MHD flow in a third-grade fluid with variable viscosity. Math. Comput. Model. 2010, 52, 1783-1793. [CrossRef]

42. Gul, T. Scattering of a thin layer over a nonlinear radially extending surface with Magneto hydrodynamic and thermal dissipation. Surf. Rev. Lett. 2019, 26. [CrossRef]

43. Ali, V.; Gul, T.; Afridi, S.; Ali, F.; Alharbi, S.O.; Khan, I. Thin film flow of micropolar fluid in a permeable medium. Coatings 2019, 9, 98. [CrossRef]

44. Liao, S. (Ed.) Advances in the Homotopy Analysis Method; World Scientific Press: Singapore, Malaysia, 2013; Chapter 7.

45. Gul, T.; Ferdous, K. The experimental study to examine the stable dispersion of the graphene nanoparticles and to look at the GO- $\mathrm{H}_{2} \mathrm{O}$ nanofluid flow between two rotating disks. Appl. Nanosci. 2018, 8, 1711-1728. [CrossRef]

46. Gul, T.; Haleem, I.; Ullah, I.; Khan, M.A.; Bonyah, E.; Khan, I.; Shuaib, M. The study of the entropy generation in a thin film flow with variable fluid properties past over a stretching sheet. Adv. Mech. Eng. 2018, 10, 1-15. [CrossRef]

(C) 2019 by the authors. Licensee MDPI, Basel, Switzerland. This article is an open access article distributed under the terms and conditions of the Creative Commons Attribution (CC BY) license (http:/ / creativecommons.org/licenses/by/4.0/). 